\title{
Susan's Career Dilemma At MGR, LLC
}

Anthony J. Mento, Loyola University Maryland, USA

Jeffrey L. Cummings, Loyola University Maryland, USA

\begin{abstract}
Professionals starting their first job after graduate school want to launch a successful career. Unfortunately, some of them soon find out that performing at a high level does not always guarantee rapid promotion or success in their organization.

This is a story about Susan, a highly recruited attorney, who joined an established law firm in Washington, DC, and was slow to realize that managing her boss is a critical skill needed for her survival and prosperity. Carlos, her direct supervisor and advocate of a tough love approach to management, views the effective nurturance and mentoring of new employees as his means of entrée into the ranks of senior partner. Carlos and Susan are on a collision course with a potential impact on both of their careers. Susan needed to decide at the end of the case what to do to strategically manage her career.
\end{abstract}

Keywords: Managing Your Boss; Conflict Management; Career Management; Career Entry; Management Style; Exercising Power And Influence

\section{INTRODUCTION}

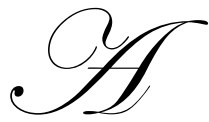

$s$ another academic year was coming to an end, Miles Morrow and Bernadette Myers were reminiscing about their Executive MBA (EMBA) students in the past year and especially in the previous years. Both had taught for many years in an EMBA program at a large state school in the mid-Atlantic region of the U.S. Since developing reflective thinking ability was central to the educational focus of this program, their attention was drawn to some of the most interesting reflection papers that students had written as part of a Leadership and Organizational Effectiveness class. While many of the papers were interesting, the focus of their attention that afternoon was inextricably drawn to the story of the novice attorney, Susan Buerhaus, who, after joining a major law firm in Washington, DC, just two years ago, was already considering leaving the firm for another. The question the young lawyer faced - should she stay or should she go - is one that many of her generation, and those who manage her generation, will increasingly be confronted with.

\section{BACKGROUND}

After two hectic years in which Carlos Espinoza, an Associate Partner and Managing Associate at Meyerhoff, Goldstein \& Rosenblatt, (MGR) LLC, sought to improve the performance of his Corporate Law (CL) practice area's ten attorneys and two paralegals, he finally believed that he could pause a moment to catch his breath as things seemed to be finally settling down. It was early March and a light dusting of snow covered the National Mall just outside his office window.

Back in the fall, one of the most experienced, fully-billable and well-published attorneys in Carlos' group, Alan Lyles, had unexpectedly passed away. As Carlos had just recently attained the position of Managing Associate but one year earlier, it fell upon him now to not only find a replacement for this dear colleague, but also to nurture the development of a recent new hire and enhance the overall performance of the CL Group. Success in his position would involve no small undertaking for Carlos as he had now, after some 20 years at the firm and having never qualified for promotion to Senior Partner status, began to rejuvenate both his career and his prospects for advancement. 
Beyond taking on a management role for the first time in his career, Carlos also needed to become more billable by developing his own practice if he was to have any chance of advancement. The truth was, while he had worked hard in many ways to help the firm enhance its administrative and governance systems and had worked diligently on the cases he was assigned, he had not done a great deal in many years with respect to advancing his legal knowledge and practice. As a result, he was a marginal performer. The last thing he needed, at this delicate early stage of his resurgence, was anyone getting in his way or making his life more difficult, both of which he began to suspect his new hire might well do.

His new hire, Susan, came to the firm just two years earlier as a highly recruited and sought after candidate. She had a number of law review publications and was considered by the firm's Senior Associates and Associate colleagues to be a real find. Hired by Carlos' predecessor, Managing Associate Rob Sapinkopf, who had been promoted to Senior Partner concomitant with Carlos' promotion to replace him, Susan's perception was that she would be entering a certain type of work environment, organizational culture and level of professional independence that made MGR more appealing than her many other options. So when the firm's founding partner, a former judge and the firm's patriarch, the Honorable Joseph R. Meyerhoff, called Carlos to inform him that Susan had indicated in a private meeting a strong likelihood that she would be leaving the firm, Carlos was both shocked and confused.

\section{SUSAN'S RECRUITMENT}

When Susan was a third-year law school student at a nationally ranked law school, she was heavily recruited by MGR and a number of other firms. Rob Sapinkopf, then Managing Associate of the CL Group and Carlos' predecessor, was the firm's initial and primary contact with Susan when she interviewed with the firm. Rob had the reputation within the firm as being extremely competent as an attorney and as a maintainer of the status quo. Rather than rocking the boat, he believed that the best way to run the CL Group was via a laissez faire policy. At executive committee meetings, Rob was seen as one who deferred taking a stand but was willing to go along with and support the position of the majority; he was considered by all a good team player. Rob's collegial, non-directive style was quite successful for the CL Group since all of the attorneys and paralegals were seasoned veterans who understood the department's expectations of getting the job done quickly and efficiently as long as the firm was not embarrassed in the public eye.

While there was historically little or no turnover in the CL Group, and recruiting for the attorney position was their first such effort undertaken in almost a decade, other practice areas within MGR had experienced much more industry-normal and higher rates of turnover. As at many law firms, turnover at MGR was widely believed to be a direct function of two key factors: the fit of the recruit with the needs and workloads of the practice area that they join, and the managerial competence of the Managing Associates who oversee and mentor the recruit's career progression from associate to partner and beyond. Thus, careful attention would be paid in recruiting processes to both the interests and acumens of the candidates, as well as their manageability or self-manageability. At the same time, with over eighty-percent of its attorneys being classified as white males, an explicit goal of MGR was to become a more diverse law firm. As such, Rob sought out and brought in for in-person interviews two other candidates along with Susan, who is a white female, including an Hispanic female and a minority male, all in keeping with the firm's nascent affirmative action perspective.

Once all three candidates had been interviewed, the CL Group met to discuss who would provide the best fit for the group. After some discussion and with consensus forming on hiring Susan, it was made clear by Rob that one of the 'more diverse' candidates would need to receive the offer. Since the male minority attorney was found to be a poor fit given his focus on and interests in practice areas of little value to the group, the Hispanic female candidate was offered the position but declined it in favor of one on the west coast. Only then was Susan offered the job.

It was not surprising that Susan was actually the lead candidate, as she had interviewed strongly, impressing everyone with her command of the legal literature and the fact that she never stumbled once when answering questions. In addition, she was clearly in control throughout her interviews; perhaps her self-assuredness arose in part from the fact that her mother was a prominent law school dean at one of the top-ranked law schools in the country and her father was a well known political figure. Susan was also very gracious in her follow-up to each 
member of the group after her interviews, expressing thanks for affording her many kindnesses during her interviews as well as suggesting future areas of practice collaboration. This style seemed somewhat reminiscent of LBJ's approach in 1941 of ingratiating himself with senators following his congressional election loss in 1940, especially to those who had opposed his candidacy (Caro, 2002).

While CL Group members understood why efforts had to be made to attract diverse candidates, they were no less all smiles when they learned a few weeks later that Susan would be joining the staff in the fall. Susan seemed quite excited as well. In the present environment of perceived catering to new hires, Susan was promised an assignment schedule that would allow her to continue her legal writing as much as one day per week, and a very limited, practically non-existent pro bono service requirement; this in a firm that routinely scheduled its attorneys annually to 2,200 billable hours, which, for most, required 55-60 hour work weeks, in addition to also fitting in up to 100 pro bono hours annually as well.

\section{CARLOS TAKES THE REINS OF THE CL GROUP}

In his over 20 years with the firm, Carlos had become a seasoned though rather marginal performer who had done little to stand out. As a result, after attaining partner status early in his career, he had never been considered for further promotion by either members of his own CL Group or the firm's senior partners. While some speculated that he could simply not penetrate the ethnic ceiling of the white male-dominated firm's hierarchy, it was also true that he routinely exhibited a level of frustration and sometimes even rage that made many feel uncomfortable with him as their group leader. Regardless, with Rob's promotion to Senior Partner and the attendant new push by the firm to advance diversity, the CL Group members championed Carlos' promotion to fill Rob's Managing Associate position, and Carlos took the reins. Finally, he would get the chance to advance further in his career, and the group members could feel good for helping support their long-term colleague.

At first, the operation of the CL Group continued as it had under Rob. This was not surprising since the attorneys in every part of the firm, as in most firms, worked fairly independently, only needing to coordinate their activities at most once a week if not on the same case, and even then perhaps only a few times per week. Moreover, both the firm and the CL Group had operated pretty much the same way for decades, with Managing Associates serving mostly as administrators helping the attorneys and paralegals coordinate what efforts needed to be coordinated and shuffling the various filings, reports and memorandums that circulated throughout their group and the firm. While the pay was somewhat higher for Managing Associates than Associates, few saw the role as anything but an undesirable though necessary service step along the path to Senior Partner. Rob exclaimed on his last day in the role, "Finally, no more meaningless paper pushing for me!"

Carlos, it seems, didn't get the memo. Instead, after a few months of getting the lay of the land, it was fair to say that Carlos embarked on nothing less than a complete redefinition of the role, fundamentally shifting it from a substantially coordinating nature to one that involved a top-down, 'do as I say' managerial posture. Not only that, but he also infused a level of enthusiasm toward the revised role that mirrored his earlier frustration/rage behavior, making many uncomfortable and concerned that they had unleashed a hierarchical nightmare. Few, it was clear, liked the idea of having dedicated sixteen years educationally and tens or more professionally, only to have someone, especially someone with Carlos' track record and experience background, begin to boss them around. Of course most, given their years of training and experience and comfortable with the own professionalism, were able to handle the situation without significant issues; they simply went about their work in the way they always had, ignoring any directives they deemed inappropriate or over-zealous, knowing full well that things would soon settle back to normal.

Most, that is, except for Susan, the novice attorney whom Carlos seemed to believe represented a perfect case subject against which to test out his new managerial style. Too bad for Susan, as not only was Carlos weak in basic managerial experience or competencies, he was also feeling his oats as he, perhaps for the first time in his professional life, felt authoritative power within his grasp. 


\section{SUSAN'S FIRST TWO YEARS IN CL GROUP OF MGR}

Susan arrived in DC in the fall with an impressive set of quality law journal publications and the hope of a promising future with MGR. During her first year, Susan performed well with clients and received a coveted award for her writing in a top law journal. Initial impressions of her first year on the job were that she was a superb attorney and a legal scholar with promise who was genuinely interested in improving. She also seemed collegial enough, regularly working with two veteran CL Group attorneys on significant, complicated cases, discussing potential collaborations with others regarding her law journal writing, and participating voluntarily in several pro bono cases with colleagues in another group. Several of the clients on the cases she supported also heaped praise on her efforts, a not-so-common level of performance among first year associates. There was great hope, therefore, that things would continue along the same, seemingly smooth path for Susan as she worked her way up the firm's legal ladder.

Unbeknownst to most of the CL Group members, however, soon after joining the firm Susan had begun experiencing consistent, sometimes innocuous but regularly annoying supervisory-type interactions with Carlos. Sometimes these interactions related to Carlos' expectations about Susan's daily duties and presence physically in her office. This was concerning to Susan because Rob, who of course had by now been promoted out of the CL Group, led her to believe during her recruitment that her time in the office could be as little as three days a week, thereby avoiding a lengthy commute to the office from her home 2 hours a way. Other times, Carlos would direct Susan to join onto or offer her support to one of MGR's numerous pro bono teams, despite her already numerous pro bono commitments and her initial pre-hiring beliefs that she would have little if any such commitments. Worse, Carlos regularly leveled threats at Susan regarding how he planned to punish her on her performance appraisal if she did not do as he directed. Thus, on an almost weekly or bi-weekly basis, Susan felt bullied, threatened or maligned by Carlos, her boss.

As if this all was not bad enough, in the fall of Susan's second year, the undercurrent of bad vibes between her and Carlos rose to a new level. After performing admirably on her case work during her first year, Susan was excited to be offered opportunities by two senior colleagues to begin work on two cases that were a wonderful fit between her legal acumen and interests. While she was uncomfortable with how she was being treated by Carlos, at least she felt she had the law, and some exciting cases, to hold her interests. Maybe if she just continued to prove herself Carlos would eventually relent and begin to treat her the way he appeared at least to be treating other members of the group. So she dedicated herself to prepping for these new cases, committing extensive overtime hours for the better part of two months, much of it off the clock, to make sure she could continue to impress both her colleagues and clients.

Two weeks before the formal launch of her participation in both cases, however, Carlos called her into his office and informed Susan that she was being reassigned to work on cases outside her own perceived comfort zone and area of expertise. Asked why the change was needed, Carlos first stated that it was because of the recent death of their colleague. When Susan attempted to inquire further, knowing full well that this colleague's practice touched on neither of the sets of relevant cases, Carlos flew-off-the handle, becoming verbally abusive and threatening, so Susan dropped the issue with Carlos. Furious at both the reassignment and her treatment by Carlos, however, Susan began asking around to see if she could find out what might have transpired. What she discovered was not just disappointing, but so much so that she began to wonder whether she should continue to work at the firm. For it seemed the real reason for her reassignment had as much to do with Carlos weak planning and management skills as with her departmental colleagues' utter disinterest in anything other than their own parochial self interests. While Susan had indeed not been singled out for potential reassignments, others, because of their status within the group, had been able to avoid both any similar reassignments and Carlos' rage. Fundamentally, Susan was told by her colleagues in hushed conversations that Carlos repeatedly missed deadlines, turned in poorly drafted forms, and then seemingly lurched wildly about for solutions to the scheduling nightmare that he created. Sure, they said, they each could have taken on some of the burden to help smooth things out; but Carlos would likely repeat such a performance on a regular basis, so they wanted as little to do with it and with him as possible.

Susan was stunned. In essence, it seemed that her colleagues were fully cognizant of Carlos's shortcomings as a fallible human being, but as long as he didn't spoil their good situation, they would just plan to 
keep their heads in the sand and let come what may. She had also raised her concerns with group members about her treatment by Carlos, how he appeared to be threatening, bullying and full of rage toward her, indicating that her relationship with him had so deteriorated that she was afraid to open her emails from him, expecting yet another blast of often poorly worded hostility aimed at her. Finding no solace from or even interest among her direct colleagues in helping her through this situation, Susan reached out to the individual who hired her, Rob, to see if there was any chance of resurrecting her perceived pre-employment agreement the two had established with respect to what Susan could expect upon joining the firm.

Rather than taking on this issue on Susan's behalf, Rob simply advised Susan to work with Carlos to settle any grievances, and then informed Carlos of his conversation with Susan. Not surprisingly, Carlos was taken aback by this perceived "end around" on the part of Susan, and sent blasts of emails castigating her over what he saw as an imperious move and told her in person exactly how he felt about her latest maneuver. In addition, as if enough had not already transpired to turn Susan off to the CL Group and the MGR firm altogether, a virtual repeat of the case assignment-case reassignment took place again for Susan three months later. This time, Susan had again invested significant time and energy toward getting up to speed on a new area of interest, including taking an evening LLM course on the topic, only to have it unceremoniously snatched from her at the last minute.

\section{THE FINAL STRAW?}

Like many firms, MGR conducts annual performance evaluations at the beginning of the new calendar year. In contrast with Susan's testy relationship with Carlos, her performance as an attorney was unequivocally considered by all as superior. Not only had she done well by her colleagues and clients, but she had also completed highly-recognized pro bono work that generated significant positive PR for the firm, and she had continued to achieve exceptional law review publications. On an objective application of the firm's stated performance metrics, Susan would be rated level 5, the highest rating possible on a scale of 1 to 5 .

Once again, however, it seems Carlos didn't get the memo (or in this case, the performance review manual). Actually, he did indeed have the manual, but simply chose to devise a more subjective review process, allowing him the flexibility to rate Susan a level 4 and to include lengthy missives about what he described as uncollegial behavior. Dumbfounded, not buying the rationales and explanations provided on her review from Carlos, and angry about the passive aggressiveness evident in Carlos' calling the kettle black with respect to collegiality, Susan realized she needed to make a career defining decision.

\section{CASE QUESTIONS}

1. What are the work styles and personalities of Carlos and Susan?

2. How do the actions of Susan differ from Carlos' expectations?

3. What is your analysis of Susan's actions and performance to date? What mistakes has she made?

4. What is your analysis of Carlos' actions and job performance to date? What mistakes has he made?

5. What actions if any would you take if you were Susan?

\section{AUTHOR INFORMATION}

Anthony J. Mento, Ph.D., is a Professor of Management in the Department of Management and International Business in the Sellinger School of Business and Management at Loyola University Maryland. His research interests are in creativity, change management, case writing, and reflection as a technique for managerial learning. Some of his publications are in the Journal of Applied Psychology, The Journal of Management, Organizational Behavior and Human Decision Processes, The Journal of Change Management, the Journal of Management Development, the Journal of Critical Incidents, and the Journal of Executive Education. E-mail: amento@loyola.edu

Jeffrey L. Cummings, Ph.D., is an Associate Professor of International Business and Strategy in the Sellinger School of Business and Management at Loyola University Maryland. His research interests are in the areas of strategic alignment, implementing strategic-analysis and player-mapping frameworks, and selecting appropriate 
strategic alliance and R\&D partners. He has recently been published in Long Range Planning, Journal of Engineering \& Technology Management, and California Management Review. E-mail: jcummings@loyola.edu

\section{REFERENCES}

1. Argyris, C. (1991). Teaching smart people how to learn, Harvard Business Review, May/June, 24(1): 99109.

2. Caro, R. A. (2003). The years of Lyndon Johnson: Master of the senate. New York, NY. Vintage Books.

3. Clawson, J. G. (2009). Level three leadership: Getting below the surface. 4th edition. Upper Saddle River, NJ: Pearson/Prentice Hall.

4. $\quad$ Drucker, P. (2005). Managing oneself. Harvard Business Review, 83(1), 100-109.

5. $\quad$ French, J. R. P. Jr., \& Raven, B. (1959). The bases of social power. In D. Cartwright (ed.), Studies in social power. Ann Arbor, MI.: University of Michigan, Institute for Social Research.

6. Gabarro, J. J., \& Kotter, J. P. (1993). Managing your boss. Harvard Business Review, 71(3), 150-157.

7. Garvin, D. A. (2003). Learning in Action: A guide to putting the learning organization to work. Boston, MA.: Harvard Business School Publishing.

8. Heath, C., \& Heath, D. (2010). Switch: How to change things when change is hard. New York, NY.: Broadway Books.

9. Hill, L. (1994). Note: Power dynamics in organizations. 9-494-083. Boston, MA.: Harvard Business School Publishing.

10. Kotter, J. P. (1996). Leading Change. Boston: Harvard Business School Press.

11. Schlesinger, L. (1996). It doesn't take a wizard to build a better boss. Fast Company, 3 (6), Retrieved from http://www.fastcompany.com/magazine/03/boss.html.

12. Thomas, K. (1992). Conflict and negotiation processes in organizations. In M. D. Dunnette

13. and L. M Hough (eds.) Handbook of industrial and organizational psychology, $2^{\text {nd }}$ edition, vol. 3, pp 660672. Palo Alto, CA.: Consulting Psychologist Press.

14. Wilmot, W. W., \& Hocker, J. L. (2007). Interpersonal conflict ( $7^{\text {th }}$ edition). New York, NY: McGraw-Hill. 


\section{TEACHING NOTES}

\section{SYNOPSIS}

Professionals starting their first job after graduate school want to launch a successful career. Unfortunately some of them soon find out that performing at a high level does not always guarantee rapid promotion or success in their organization. Susan, a highly recruited attorney, joined an established law firm in Washington, DC, and was slow to realize that managing her boss is a critical skill needed for her survival and prosperity. Carlos, her direct supervisor and advocate of a tough love approach to management, views the effective nurturance and mentoring of new employees as his entrée to the ranks of senior partner. Carlos and Susan were on a collision course with a potential impact on both of their careers. Susan needed to decide at the end of the case what to do to strategically manager her career.

\section{TEACHING SUGGESTIONS}

This is a decision case that can be used in undergraduate and graduate courses in organizational behavior, human resource management, or specialized elective courses focusing on leadership or power and influence.

\section{Learning Objectives}

This case is best used and directed through the suggested Case Questions. After review and analysis, students should be able to:

1. Explain the role that personal work styles and politics can play in a corporation.

2. Examine the concepts of power and influence.

3. Evaluate strategies for constructive conflict resolution.

4. Apply a framework for developing a productive relationship with one's boss.

\section{Research Method}

This is a disguised case based on actual events of field data observed by the authors. Both the names and venue have been changed to protect the anonymity of the case players.

\section{Case Questions}

\section{What are the work styles and personalities of Carlos and Susan?}

Susan appeared to be an affable sort who wanted to get along with colleagues and to be a good team player when required. She is doing what she is asked to do and had made some contacts through her pro bono work. She is not required to do this type of work given her agreement with Rob but she has chosen to do so in those areas where he has a passion or interest. She is a young, ambitious, relatively accomplished, newly-minted lawyer just starting out in a law firm. Susan is transitioning from a law school academic environment to the legal department of a corporate law firm. She was heavily recruited because of her law school track record and is considered to be a very promising new hire by her Associate colleagues within the CL Groups and across parts of the organization. She came across as very self assured and as a polished presenter in her pre-employment interviews.

She was promised by Rob, the corporate law senior managing associate prior to Carlos' ascension, a work schedule significantly different than regular associates, which would allow her significant work autonomy and time to work at home, and she expected this to be part of her psychological contract. She was independent in nature and was continuing the style of work she was accustomed to in law school.

Carlos seemed to want to change the culture of the firm from one of great work independence with some teaming to an authoritative, directive way of working with him as the boss. He seemed to be harboring quite a bit of rage and can be truly frightful to colleagues who have close encounters with him. He perceived this "promotion" as a way to 
rejuvenate his career by making his department successful, starting by getting the new, promising recruit in line. While he has worked extensively in the firm's administrative and governance systems he has actually done little to advance his legal knowledge and practice. Carlos' cause was championed as managing associate by the CL group to advance the firm's nascent diversity initiative.

\section{How do the actions of Susan differ from Carlos' expectations? How might the application of Wilmott and Hocker's (2007) goal conflict model apply here?}

Susan is operating according to the model she received from Rob when she was hired. She is working independently whenever she can and is developing relationships across the organization as evidenced by her pro bono work with colleagues in departments other than the CL group. From Susan's point of view, Carlos seemed to want to be her boss, but expected her to acquiesce to his wishes. To Susan, this seems more suitable to a blue collar, more hierarchical, authoritative-type work environment, with respect to time spent in the office and willingness to drop whatever she is working on to satisfy Carlos' more immediate short-term needs. There was no clear evidence in the case that Susan was actively or consciously attempting to manage her boss.

Carlos' rather directive management style seems to be more congruent with a blue collar work environment. He attempts to use this style with Associate Partners in the CL group, but because of their experience, they ignored his demands as unreasonable and not at all compatible with the culture of a white collar service organization.

Susan might be performing up to a high level as judged by an impartial observer, but from Carlos' perspective, she was deficient on relatively minor things that he considered to be quite important.

It might be useful here to introduce the concept of interpersonal conflict, as conflicts can be caused by incompatible goals, different interpretations of the same objective facts, and disagreements based on style and behavior. Wilmott and Hocker (2007) identify the following four common types of goals that are present in interpersonal conflict:

- $\quad$ Content or topic goals focus on what each person wants. Carlos was concerned with follow-through and having others, especially subordinates, keep him in the loop. He wanted Susan to listen to him and to abide by his requests/orders. Susan wanted the freedom to work on what she was interested in as per her agreement/deal with Rob as long as the firm and its clients are the beneficiaries.

- $\quad$ Relational goals relate to how each person wants to be treated. Carlos apparently wanted Susan to treat him with deference and respect and probably wanted her to fear him to some degree so as to ensure her compliance with his demands/requests. Susan wanted not to be micromanaged and to enjoy the benefits of the professional white collar atmosphere promised to her by Rob.

- $\quad$ Identity or face saving goals have to do with the parties striving to protect their identities or characters. With Susan's proclivity for independence, and her widely recognized accomplishments in spite of Carlos' efforts to constrain or at least exercise control over her, Carlos might see this as an overt challenge to his management style and authority. This can be identified as a major source of conflict in the case.

- $\quad$ Process goals relate to how the work gets done. Carlos seems to want frequent check-ins by Susan on her work progress and performance, as well as her willingness to turn on a dime to meet his short-term and unexpected needs, frequently arising due to poor planning on his part. Susan prefers to focus on her longer-term career aspirations by developing expertise in targeted areas and working with and bringing along colleagues on her research efforts.

As a result of one or more of these differences in goals or other sources of interpersonal conflicts with Carlos, including her punishing interactions with him by email and in person, Susan seemed to be following a strategy of avoidance and disassociation. At the same time, Carlos, in part likely due to Susan's avoidance posture, seemed to be pushing harder than ever to exert his authority over her. 
3. What is your analysis of Susan's actions and performance to date? What mistakes has she made? Please consider French and Raven's (1959) approach to power or Hill's (1994) analysis of positional and personal power in formulating your response.

During Susan's first two years, clients heaped praise on her efforts, a relatively uncommon occurrence among new associates. Also, Susan won a coveted award for her writing in a top law journal. It should be noted that Susan also received positive feedback from two veteran CL attorneys and was perceived across the firm or at least in the CL department as a superb attorney with a very positive future with the firm. She has continued with her exceptional law review publications and completed highly-recognized, voluntary pro bono work that generated positive public relations for the firm. Objectively, and under normal circumstances, Susan seemed to be on track to advance quickly within the firm.

Susan has not tried to overtly manage her boss; she has not investigated in any depth what motivates Carlos and what his needs and expectations are for her. She is independent and does not try to reach any common ground with Carlos. She did not seem to realize that part of her job is to understand Carlos' needs and pressures, and to help him with these issues. Although Susan neither perceived nor understood Carlos' needs as her boss, she seems to have developed some important and necessary relationships within the department and across the firm that should help her survive in the organization.

Argyris (1991) might describe Susan as a smart, successful person who has rarely experienced failure or even underperformance and consequently is incapable of double-loop learning, which requires one to assess their basic assumptions. According to Argyris, very successful individuals tend to lack significant introspective ability and tend to attribute the source for any performance shortcomings to be others (looking out the window) rather than themselves (reflecting in the mirror). Related to this way of thinking, Susan might be guilty of committing the fundamental attribution error. This error lies in our inclination to attribute people's behavior (in this case Carlos') to the way they are rather than to the circumstances they are in (Heath and Heath, 2010).

In a political situation such as that in which Susan is involved, understanding sources of power is important in analyzing appropriate actions. French and Raven's (1959) classical theory of social power can be presented and applied in Susan's situation. Both expert and referent power could have been utilized to Susan's advantage.

- $\quad$ Expert power is power based on expertise or knowledge. Followers comply because they are confident in the expert's knowledge. Susan has become recognized as an accomplished author in prestigious law journals, something that might be exploited as being important to the firm and not just to Susan's resume. She has also created goodwill for the CL department across the firm for her pro bono work with associates in different departments as well as generated positive client feedback based on her work.

- $\quad$ Referent power is based on an individual's feelings about the person making the request. With referent power, followers comply if they have enough positive regard for the influencer so that they believe, "this person deserves my support/cooperation". Susan has used referent power to develop contacts and linkages in other parts of the organization but not nearly to the extent that she might have. This source of power could be a major source of leverage for Susan in determining her career progress.

Two other types of power might usefully be discussed with respect to Carlos' situation.

- $\quad$ Legitimate power is based on an individual's view of his or her position in the group. With legitimate power, members willingly comply since they believe doing so is part of their position's "job requirements". As Susan's direct supervisor, Carlos has utilized this power base to evaluate Susan's performance and to assign her specific cases to work on.

- $\quad$ Coercive power is power based on fear. Followers comply because they believe that the person making the request could (and would) cause them to be punished if they fail to obey. Carlos has used coercive power a number of times with Susan in his personal and electronic interactions with her, attempting to use this power base to keep her in line with his expectations of a new associate. 
One other type of power is reward power. Reward power is based on the desire to obtain some sort of extrinsic reward which involves controlling the apportioning of formal and informal rewards to individuals. This is not really a relevant factor in the case, as Carlos does nothing to praise or reward Susan for her rather exceptional performance during her first two years on the job.

For a further elaboration regarding power as applied to Carlos' situation, Hill's (1994) work on positional and personal power can be useful. Positional power refers to power accrued to an individual as a function of their location in an organization. Its sources and their application to Carlos' situation include:

- $\quad$ Formal authority, which stems from one's roles and responsibilities within an organization; Carlos automatically has this as a function of his role as managing associate.

- $\quad$ Relevance, which relates to the strength of the relationship between certain tasks and organizational objectives; Carlos might be perceived as relatively low on this power source as perceived by associates since a great deal of their work is independently pursued and self-managed.

- $\quad$ Centrality, which is the position of an individual within key communication and coordination networks; one would expect that Carlos would have developed this power source as a result of his tenure in the organization, although his prior weak performance might have stifled his ability to gain in this regard.

- $\quad$ Autonomy, which is about the degree of discretion a position allows with respect to decision making, work efforts, etc.; relative to other lawyers in the department, Carlos' autonomy to control or direct other lawyers is not very high since, by the nature of the work, most associates have or believe they should have a high degree of autonomy themselves, so any supervisors are by definition limited in their own autonomy over them.

- $\quad$ Visibility, which is the degree to which performance can be seen by others; this does not seem to be a significant source of power for Carlos.

Hill's (1994) second type of power, personal power, is the power one develops as a function of the activities they perform. As applied to Carlos' situation, personal power stems from four sources:

- $\quad$ Expertise, with respect to having relevant knowledge and skills; this does not appear to be a significant source of power for Carlos, but may well be for Susan.

- $\quad$ Track record and relevant experience; this does not appear to be a significant power source for Carlos, although Susan's exceptional performance may have her believe that she possesses some of this type of power over Carlos.

- $\quad$ Attractiveness, or attributes others find appealing and identify with; as evidenced by his rage behavior, it is unlikely Carlos is attractive to key stakeholders in the organization.

- $\quad$ Effort, or expenditure of time and energy; Carlos does not seem to possess this type of power despite the time and energy he has expended in the organization over many years, as his efforts were not directed at areas, namely client work and legal writing, most valued by the firm's members.

It might be useful here to develop a compare and contrast between Susan and Carlos' powers across each of the different types of power. When such a power analysis is conducted with respect to positional and personal power, for example, Susan seems to clearly have more personal power than Carlos, while Carlos generally trumps her on positional power. Interestingly, it may well be in those areas where Susan's powers trump Carlos' powers lies the root of many of their conflicts. 
4. What is your analysis of Carlos' actions and job performance to date? What mistakes has he made? Here it might be useful to keep in mind Kotter's (1996) distinction between leadership and management.

Carlos has been a relatively marginal performer his whole career. He has recently attempted to rejuvenate it by taking the thankless job of Managing Associate for the CL Group. He seemed to be fairly strong administratively when not charged with direct supervision of attorneys. Carlos' culture-bending/breaking behavior towards his CL associates and Susan in particular seemed to be especially troubling. It seemed clear that Carlos is weak both as a manager and as a leader as differentiated by Kotter (1996). With respect to management, Carlos demonstrates minimal skills in planning, staffing, organizing, and controlling. With respect to leadership, activities in which Carlos appeared lacking are developing a compelling vision, aligning employees towards the vision, and bringing about important critical change for improving his department's effectiveness. Also puzzling is the reluctance of the partner associates to call Carlos on his behavior in dealing with Susan.

Carlos demonstrated a number of weaknesses. First, he was using an inappropriate style of management given the nature and culture of the organization. Why he seems to somewhat relentlessly pursue his power play with Susan cannot really be known without delving into a deep psychological assessment of his motivation. It may be that in the persona of Susan, Carlos sees the archetypical white Anglo Saxon who in his experience and career at the law firm has always had it easy and gotten all of the breaks. It is also probably true that Carlos did not perceive Susan as a valuable resource and as a potential enabler for him to accomplish his short and long-term agendas for the department and the firm. Second, Carlos apparently did not work with and ask for assistance from more experienced managing associates in other parts of the firm with a demonstrated track record of nurturing promising young lawyers to the partner level. Another weakness to consider is that he did not ask for help or assistance from colleagues within the CL department who were confidants and in some cases mentors of Carlos. We remember that he had worked with and knew all department members at least 10 years and in some case 20.

5. What actions if any would you take if you were Susan? It would be useful here to consider Thomas' (1992) model of conflict management, Gabarro and Kotter's (1993) work on managing your boss, as well as Schlesinger's (1996) recommendations for working with different types of bosses.

It is useful to consider the different conflict styles available to Susan to help decide which approach is most appropriate given the situation. One can think of a two by two matrix with Assertiveness on the $\mathrm{Y}$ axis and Cooperativeness on the $\mathrm{X}$ axis (Thomas, 1992). The different conflict styles include the following:

- $\quad$ Competition (low on cooperativeness and high on assertiveness) is characterized by aggressiveness and uncooperative behavior. This would seem to be a very risky strategy to pursue considering Carlos' sole source of power is positional. It also does not seem to be the nature of Susan to pursue this aggressive approach to conflict resolution.

- $\quad$ Compromise (medium on both cooperativeness and assertiveness) is a middle road on which battles are mostly dealt with by bringing out challenging behavior only when needed. This seems to be a way for Susan to adapt and prosper. She could adapt to Carlos' work style to more closely fit those areas that he is extremely concerned about. Of course this would entail Susan doing a relatively in depth analysis to understand the values, assumptions, beliefs, and expectations of Carlos. As long as Carlos is her supervisor Susan must develop a way of working with Carlos in a satisfactory manner.

- $\quad$ Avoidance (low on both cooperativeness and assertiveness) is a strategy of disassociation. Susan has been warned by Rob and the head of the firm, Joseph Myerhoff, that that she must deal with her problems with Carlos herself within her department. Isolating herself and cutting off interactions with Carlos is likely to only produce more dysfunctional effects for Susan.

- $\quad$ Accommodation (high on cooperativeness and low on assertiveness) involves substantially accepting guidance and direction with minimal pushback. This might be an acceptable approach for Susan if she can clearly see the benefits of complying with Carlos' wishes. 
- $\quad$ Collaboration (high on both cooperation and assertiveness). Susan must be willing here to at least meet Carlos half way to determine his goals and expectations while Carlos must be willing to accommodate Susan to a degree. Working together they could possibly identify ways to work with each other to create a win-win environment of respect and cooperation.

Another approach that Susan might take is to attempt to deliberately manage up the relationship with Carlos by realizing that they both are dependent on each for accomplishing personal, departmental, and organizational goals. It is crucial especially for new employees like Susan to actively manage her relationship with Carlos in order to produce benefits for all concerned parties. She can begin to do this by focusing on understanding Carlos' specific context, to include his strengths and weaknesses, the pressures he feels from above and from his peers, and the combination of organizational and personal objectives he is trying to meet. This entails mentally shifting one's framework away from "I" to a broader world that includes "us." Gabarro and Kotter (1993) remind us that developing effective work relationships with one's boss should not be viewed as political but rather as another important relationship to manage, like managing one's customers which are crucial for business success.

Some specific things that Susan might have done were to clarify goals and expectations that Carlos had for her and to check regularly to determine if these changed over time. It is essential for Susan to have determined Carlos' personal objectives to ensure that she does not consciously work against them. Another aspect of learning how to work more effectively with Carlos would be to assess his work style. Some areas which could be focused on include:

- Does Carlos prefer a more organized and formal approach when meeting or was it acceptable to stop him in the hall at any time to convey important information?

- $\quad$ How does Carlos prefer to receive information (i.e., is he a listener or a reader)?

The overall goal here is to learn how to work best to accommodate a boss rather than bend one's personality to theirs.

Another approach to analyzing how to best work with Carlos can be found in Schlesinger (1996). Using characters from the Wizard of $\mathrm{Oz}$, he suggests how to learn and grow from working for a boss best described as a scarecrow, a cowardly lion, or a tin man. For example, if one is working for a scarecrow (a boss without brains), there exists an opportunity, if one is allowed considerable autonomy, to act like a leader. This entails analyzing a situation, determining what needs to be done, then taking action and asking for forgiveness after the fact rather than permission to act (Clawson, 2009). Susan might then be sure to attribute value-added contributions to the organization to Carlos. A different scenario unfolds when one is working for a cowardly lion that refuses to take a stand. When encountering this particular situational dynamic, one's sense of passion for an issue is heightened, thereby helping one determine where their passion lies and what is really important and worth battling over. Then it would be up to Susan to activate her passion by marshalling all necessary information, resources and support to provide a compelling business case for a proposed course of action.

A third type of boss Susan needs to learn to work with is the tin man, the cold, aloof boss seemingly without feeling or emotion with respect to relationship issues. In this situation, the boss' passion might lie with the business but not in being interpersonally competent. Carlos seems to fit this archetype. Susan might have learned and benefited most from this type of boss-subordinate relationship by concentrating on the specific feedback and content of the feedback provided by the boss, rather than the process of delivery. Practice in dispassionately receiving strong, objective feedback can develop mental toughness in Susan. It could also tangentially lead to the development of a support network cutting across the organization that does not include her boss. The essence of Schlesinger's work is to view the boss-subordinate relationship in a positive frame with the perspective that one need not be a passive recipient of organizational circumstances. If one chooses to be proactive rather than passive, one might be able to learn from different types of bosses and thus be better able to actively manage their career.

Managing up also involves taking responsibility for a situation to best place you in a position to maximize your strengths. Drucker (2005) suggests that the best way to determine one's strengths is through effective feedback 
analysis. This might involve a detailed After Action Review (AAR) (Garvin, 2003) conducted regularly after significant organizational events in which one is a key player. By answering a series of questions and reflecting on the answers, one is well placed in explicitly becoming aware of strengths and weaknesses. AAR questions might be:

- What was the individual trying to do?

- What happened?

- Why did it happen?

- What should be sustained?

- What should be changed?

- What was learned by working through this AAR?

If Susan undertakes a proactive approach to continually reflecting and systematically learning from past events and deliberately applying this learning to new situations, she will be well positioned to thrive in any organizational context working with many different types of bosses. 
Journal of Business Case Studies - November/December 2011 Volume 7, Number 6 NOTES 